\title{
Studi Kualitatif Perilaku Masyarakat dalam Pencegahan Malaria di Manokwari Barat, Papua Barat, Indonesia
}

\section{Qualitative Study of Community Behavior in Malaria Prevention in West Manokwari Sub-District, Manokwari District, West Papua Province}

\author{
Nilce Astin ${ }^{1)}$, Andi Alim ${ }^{1)}$, Zainuddin ${ }^{1)}$ \\ 1 Fakultas Kesehatan Masyarakat, Universitas Pejuang Republik Indonesia
}

Email: andi_alimbagu@yahoo.co.id

\begin{abstract}
Background: In Indonesia, Malaria is still a public health problem. Based on health data from West Papua Province, as of August 2018, there were 4,182 Malaria cases in West Papua Province. Of these, 2,346 cases of Malaria occurred in Manokwari District or nearly $50 \%$. In second place is South Manokwari Regency with 692 cases and third, Teluk Wondama District with 286 cases. Objective: This study aims to explore information about Malaria prevention efforts in the community in West Manokwari Sub-district, Manokwari District. Methods: This study used a qualitative method with a phenomenological approach. Research informants were 9 people who were determined by the snowball technique, the informants consisted of 8 residents who live in West Manokwari Sub-district and 1 health worker from the community health centre that handles the Malaria program. Results: This study shows that Malaria prevention efforts by killing adult Malaria larvae and mosquitoes through spraying houses, larviciding and biological control have never been carried out by the community because they assume this is the responsibility of health workers. To prevent Malaria mosquito bites against those who have the habit of being outside at night by wearing long-sleeved $T$-shirts, jackets and long sarongs. The use of mosquito nets during night sleep is still done but is not used routinely, only occasionally and some even do not use mosquito nets at all. The use of anti-mosquito repellent types of mosquito coils, in addition to saving, is also affordable. The use of wire mesh was not carried out, because some community houses were still semi-permanent whose windows were made of boards and used clear plastic and cloth as curtains for window coverings. Conclusion: Efforts to prevent Malaria by the community are not carried out consistently and thoroughly because there is an assumption that efforts to eradicate Malaria are the responsibility of health workers.
\end{abstract}

Keywords: Malaria Prevention, Community Behavior, Health Services

\section{ABSTRAK}

Latar Belakang: Malaria di Indonesia sampai saat ini masih merupakan masalah kesehatan masyarakat. Dinas Kesehatan Provinsi Papua Barat menyebutkan, hingga Agustus 2018, tercatat 4.182 kasus Malaria di Provinsi Papua Barat. Dari jumlah tersebut, 2.346 kasus Malaria terjadi di Kabupaten Manokwari atau hampir 50\%. Di urutan kedua ditempati Kabupaten Manokwari Selatan dengan 692 kasus dan ketiga, Kabupaten Teluk Wondama dengan 286 kasus. Tujuan: Penelitian ini mempunyai tujuan untuk mengeksplorasi informasi tentang upaya pencegahan Malaria pada masyarakat di Kecamatan Manokwari Barat Kabupaten Manokwari. Metode: Penelitian ini menggunakan metode kualitatif dengan pendekatan fenomenologi. Informan penelitian sebanyak 9 orang yang ditetapkan dengan teknik snowball, informan tersebut terdiri 8 orang warga yang berdomisili di Kecamatan Manokwari Barat dan 1 orang petugas kesehatan dari Puskesmas yang menangani program Malaria. Hasil: Penelitian ini menunjukkan bahwa upaya pencegahan Malaria dengan cara membunuh jentik dan nyamuk Malaria dewasa melalui penyemprotan rumah, larvaciding dan biological control tidak pernah dilakukan oleh masyarakat karena anggapan hal ini merupakan tanggung jawab petugas kesehatan. Untuk mencegah gigitan nyamuk Malaria terhadap mereka yang memiliki kebiasaan berada di luar rumah pada malam hari dengan cara memakai pakaian baju kaos lengan panjang, jaket, dan sarung 
panjang. Penggunaan kelambu saat tidur malam tetap dilakukan akan tetapi tidak digunakan secara rutin, hanya sesekali dan bahkan ada yang tidak menggunakan kelambu sama sekali. Pemakaian obat anti nyamuk jenis obat nyamuk bakar, selain karena hemat juga harganya terjangkau. Pemakaian kawat kasa tidak dilakukan, sebab sebagian rumah masyarakat masih semi permanen yang jendelanya terbuat dari papan dan memakai plastik bening serta kain sebagai gorden sebagai penutup jendela. Kesimpulan: Upaya pencegahan Malaria oleh masyarakat tidak dilakukan secara konsisten dan menyeluruh karna adanya anggapan bahwa upaya pemberantasan nyamuk Malaria merupakan tanggung jawab petugas kesehatan.

Kata Kunci: Pencegahan Malaria, Perilaku Masyarakat, Pelayanan Kesehatan

\section{PENDAHULUAN}

Malaria tergolong penyakit menular yang disebabkan oleh parasit dari genus plasmodium yang ditularkan melalui gigitan nyamuk Anopheles betina. Penularan Malaria dapat juga terjadi dari orang yang sakit kepada orang sehat melalui gigitan nyamuk. Bibit dari penyakit Malaria ini yang terdapat dalam darah orang sakit ini terhisap oleh nyamuk kemudian berkembang biak di dalam tubuh nyamuk tersebut, kemudian nyamuk tersebut kembali mengigit orang yang sehat sehingga menderita Malaria.

Kasus Malaria hampir ditemui diseluruh dunia, khususnya negara-negara beriklim tropis dan subtropis, oleh karena itu, penduduk berisiko terkena Malaria diperkirakan mencapai 2,3 miliar atau 41\% dari jumlah penduduk di dunia. Sebanyak $35 \%$ dari populasi dunia tinggal di daerah yang berisiko penularan Plasmodium falciparum, dan sekitar 1 milyar orangorang yang tinggal di daerah yang berisiko rendah dan masih ada penularan Malaria (Arsin, 2012).

Kejadian Malaria di Indonesia diperkirakan sebanyak 4,9 juta dari 262 juta penduduk. Kasus Malaria pada tahun 2017 tercatat 261.617 kasus yang telah mengakibatkan kematian setidaknya 100 orang. Sebanyak setengah dari jumlah 514 kabupaten/kota di Indonesia sudah mencapai kategori bebas Malaria. Artinya, terdapat 72 persen penduduk di Indonesia tinggal di daerah bebas Malaria (Kemenkes RI, 2017).

Peta situasi Malaria warna putih atau bebas Malaria terdapat di Pulau Jawa dan Bali, sementara sisanya mayoritas berwarna hijau (endemis rendah) seperti di Sumatera, Kalimantan, dan Sulawesi. Sebagian daerah di wilayah Indonesia timur masih berwarna merah atau endemis tinggi dan kuning atau endemis menengah. Daerah merah dan kuning tersebut masih banyak terdapat di wilayah timur Indonesia, antara lain Papua dan Papua Barat, Nusa Tenggara Timur, dan beberapa area Kalimantan (Kemenkes RI, 2017).

Khusus di Papua Barat, upaya penemuan kasus Malaria masih bersifat pasif. Data Dinas Kesehatan Provinsi Papua Barat menyebutkan, hingga Agustus 2018, tercatat 4.182 kasus Malaria di Provinsi Papua Barat, dan 2.346 kasus Malaria terjadi di Kabupaten Manokwari atau hampir 50\%. Di urutan kedua ditempati Kabupaten Manokwari Selatan dengan 692 kasus dan ketiga, Kabupaten Teluk Wondama dengan 286 kasus (Dinas Kesehatan Provinsi Papua Barat, 2018).

Kabupaten Manokwari sebagai salah satu kabupaten yang sedang dalam masa perkembangan tentunya tidak dapat secara langsung mempengaruhi perilaku masyarakat dalam upaya penanggulangan Malaria. Berbagai perilaku masyarakat yang ada akan mempengaruhi gaya hidup, sebagai contoh kebiasaan berada di luar rumah pada malam hari ini dapat memudahkan untuk digigit nyamuk Anopheles. Sebagian masyarakat tidak mau memakai kelambu insektisida dengan alasan panas, di sisi lain masih ada juga penderita Malaria yang tidak konsisten minum obat Malaria. Kebiasaan tersebut tentu dapat mempengaruhi kejadian kasus Malaria di Manokwari, selain itu belum pernah ada penelitian yang dilakukan untuk menganalisis pengaruh faktor perilaku masyarakat atau gaya hidup (life style) terhadap kasus Malaria. Karakteristik masyarakat Manokwari yang sebagian besar bermata pencaharian sebagai nelayan tentu terbiasa berada di luar rumah pada malam hari. Mereka beranggapan sudah terbiasa 
digigit nyamuk jika hanya mengenakan baju/celana pendek. Mereka hanya menghindari gigitan nyamuk apabila sedang berada di dalam rumah/saat tidur malam saja. Mereka juga memakai obat anti nyamuk bakar jika tidur malam supaya tidak digigit nyamuk dan apabila terjadi atau ada anggota keluarga mereka yang mengalami gejala Malaria, mereka terkadang menangani sendiri dengan membeli obat di apotek dan apabila gejala yang dirasakan tidak berubah/sembuh baru datang ke fasilitas kesehatan.

Karakteristik masyarakat di atas kemungkinan menjadi faktor penyebab sehingga penanganan Malaria tidak berjalan secara maksimal, oleh karena itu melalui penelitian ini akan mengungkap determinan perilaku terhadap kasus Malaria pada masyarakat di Kecamatan Manokwari Barat tahun 2019. Perilaku masyarakat yang dimaksud dalam penelitian ini yaitu kebiasaan masyarakat berada diluar rumah pada malam hari, penggunaan kelambu pada saat tidur, pemakaian obat anti nyamuk serta pemasangan kawat kasa pada jendela dan ventilasi rumah. Penelitian ini bertujuan untuk mengeksplorasi informasi tentang upaya pencegahan Malaria pada masyarakat di Kecamatan Manokwari Barat Kabupaten Manokwari.

\section{METODE}

kualitatif dengan pendekatan fenomenologi yang bertujuan untuk menggali informasi secara mendalam tentang upaya pencegahan penyakit Malaria yang dilakukan oleh masyarakat di Kecamatan Manokwari Barat. Lokasi penelitian adalah Kecamatan Manokwari Barat, Kabupaten Manokwari, Provinsi Papua Barat.

Informan dalam penelitian ini sebanyak 9 orang yang ditentukan dengan teknik snowball. Informan tersebut terdiri dari 8 orang warga yang berdomisili di Kecamatan Manokwari Barat dan 1 orang petugas kesehatan yang menangani program Malaria di Puskesmas Wosi yang berada di Kecamatan Manokwari Barat.

Cara pengumpulan data yang digunakan yaitu data primer dilakukan dengan cara wawancara mendalam (indepth interview) terhadap informan dengan menggunakan pedoman wawancara. Pengumpulan data sekunder diperoleh dengan cara membaca laporan dari instansi terkait yang berhubungan dengan penelitian ini. Observasi (pengamatan) dilakukan dengan mengamati langsung lokasi penelitian dan informasi dari informan. Pengolahan dan penyajian data dilakukan dengan mengumpulkan semua data/informasi yang sama dan dapat mewakili informasi yang diinginkan. Setelah berbagai data terkumpul, maka untuk menganalisisnya digunakan teknik analisis kualitatif meliputi tiga unsur yaitu reduksi data, penyajian data, dan penarikan kesimpulan untuk menggambarkan kembali data-data yang telah terkumpul mengenai perilaku pencegahan Malaria yang dilakukan oleh masyarakat. Data yang sudah diolah kemudian disajikan dalam bentuk naskah (narasi).

\section{HASIL DAN PEMBAHASAN}

Karateristik informan menunjukkan sebagian besar berjenis kelamin perempuan sejumlah 7 orang dan laki-laki sejumlah 2 orang, umur informan dominan kategori 20-40 tahun dan hanya 1 orang yang kategori 41-50 tahun, mayoritas informan merupakan ibu rumah tangga, dengan suami yang bekerja sebagai buruh kasar dan nelayan yang dalam kebiasaan sehari-harinya selalu beraktivitas di luar rumah pada malam hari.

\section{Upaya Memberantas Jentik dan Nyamuk Dewasa}

Upaya yang dapat dilakukan untuk membunuh jentik dan nyamuk dewasa, antara lain penyemprotan insektisida pada sekitar rumah khususnya daerah endemis Malaria sekurang-kurangnya dua kali dalam setahun dengan interval waktu enam bulan. Larvaciding dilakukan dengan cara menyemprot daerah rawa-rawa yang memiliki potensi menjadi tempat perindukan nyamuk Malaria. Biological control dilakukan dengan penebaran ikan kepala timah dan guppy dengan harapan ikan tersebut dapat menjadi pemangsa jentik nyamuk Malaria (Kemenkes RI, 2014).

Hasil penelitian menunjukkan bahwa sebagian besar informan jarang melakukan upaya membunuh jentik dan nyamuk dewasa. Kondisi ini terjadi karena mereka tidak memiliki bahan untuk melakukan penyemprotan di sekitar 
rumahnya. Informan menganggap bahwa penyemprotan biasanya dilakukan oleh petugas kesehatan. Kegiatan penyemprotan insektisida di wilayah kerja puskesmas Wosi sesungguhnya rutin dilakukan namun diprioritaskan pada daerah dengan kasus Malaria tinggi. Petugas puskesmas akan turun melakukan penyemprotan jika ada warga yang datang melaporkan kasus Malaria di wilayahnya. Kegiatan larvaciding dan biological control sama sekali tidak pernah dilakukan oleh masyarakat sebab mereka belum tahu dan belum memiliki dalam menerapkan metode tersebut. Larvaciding dan biological control hanya dilakukan oleh petugas kesehatan, namun tindakan tersebut dilakukan jika terjadi Kejadian Luar Biasa (KLB), sementara di Kecamatan Manokwari Barat dalam beberapa tahun terakhir tidak pernah terjadi KLB. Kegiatan penyemprotan insektisida selama ini hanya dilakukan oleh petugas kesehatan, namun dalam tiga tahun terakhir ini tidak ada petugas yang datang menyemprot. Kondisi tersebut disebabkan karena masyarakat jarang ada yang mau melaporkan kasus Malaria bila ada keluarganya yang menderita Malaria. Mereka lebih cenderung membeli obat langsung di apotek jika merasa sedang mengalami gejala Malaria. Penyakit Malaria sudah dianggap biasa terkecuali bagi mereka yang sudah terlanjur parah datang ke puskesmas untuk berobat. Seperti pada kutipan wawancara berikut ini:

"Tara pernah jo, tara pernah sama sekali disemprot disini so 3 tahun tinggal disini, mau semprot sendiri tarada bahan, tara pernah liat juga petugas datang semprot nyamuk, warga disini beli obat sendiri saja di apotek kalo ada sakit Malaria, kita sudah tahu juga toh oba'nya' biasa dikasi minum klo ada sakit Malaria tong nanti baru ke puskesmas klo tidak sembuh." (NC, 35 tahun).

Sebagian besar masyarakat sudah mengetahui gejala dan tanda-tanda penyakit Malaria serta cara pencegahan yang efektif seperti penyemprotan insektisida, namun hal tersebut tidak dilakukan. Masyarakat berharap kepada petugas kesehatan yang melakukan penyemprotan, sementara petugas hanya menyemprot pada kampung-kampung atau kelurahan dengan kasus yang tinggi. Sebagaimana kutipan pernyataan informan berikut:

"Tara pernah. Tara pernah selama ini, tinggal disini so lama tara ada petugas datang menyemprot di rumah." (RB, 30 tahun).

Informan menyatakan bahwa selama dia tinggal di Kecamatan Manokwari Barat, tidak pernah dilakukan penyemprotan rumah, larvaciding atau biological control.

"Tara pernah, tara ada penyemprotan, solama sekali itu, pemberian obat juga tara pernah." (HM, 45 tahun)

Informan menyatakan bahwa sudah lama petugas tidak melakukan penyemprotan nyamuk, larvaciding dan biological control.

"Tara pernah semprot, tara adada petugas datang, mau lapor juga susah puskesmas jauh, biaya lagi datang kesana. Larvaciding, biological control tra tahu, mau bikin apa, tara tahu juga." (BM, 32 tahun).

Hasil wawancara terhadap seluruh
informan menunjukkan bahwa penyemprotan insektisida, larvaciding, dan biological control membunuh jentik dan nyamuk dewasa tidak pernah dilakukan. Mereka berharap aktivitas tersebut dilakukan oleh petugas kesehatan karena itu sudah menjadi tanggung jawabnya. Masyarakat juga tidak mengetahui cara untuk melakukan larvaciding dan biological control. Informan juga mengaku bahwa ia tidak memiliki biaya untuk melakukan pelaporan apabila terjadi kasus Malaria di puskesmas karena lokasinya yang jauh.

Tidak adanya penyemprotan untuk seluruh rumah yang ada di Kecamatan Manokwari Barat dibenarkan oleh petugas kesehatan di Puskesmas Wosi karena penyemprotan/spraying hanya dilakukan jika terjadi KLB (Kejadian Luar Biasa). Penyemprotan yang rutin dilakukan hanya diprioritaskan pada daerah dengan kasus Malaria yang tinggi. Petugas juga turun melakukan penyemprotan jika ada warga yang datang melaporkan kasus Malaria di wilayahnya. Keterbatasan petugas 
lapangan di puskesmas juga menjadi salah satu faktor sehingga aktivitas tersebut tidak dilakukan. Kemampuan untuk menyiapkan bahan dan alat juga menjadi salah satu kendala sehingga tidak melakukan larvaciding dan biological control di wilayah kerjanya. Pernyataan tersebut seperti pada kutipan hasil wawancara berikut ini:

"Kalau Malaria itu penyemprotan dengan menggunakan insektisida, spraing namanya. Itu nanti dilakukan jika terjadi KLB. Manokwari belum pernah terjadi $K L B$, kematian pun so tidak perna. Jumlah petugas di puskesmas juga kurang dan tidak ada petugas di lapangan yang mampu menyiapkan bahan dan alat untuk melakukan larvaciding dan biological control di Puskesmas Wosi." (IW, 25 tahun)

Upaya pencegahan Malaria di Puskesmas Wosi yang merupakan layanan kesehatan tingkat pertama yang berada di Kecamatan Manokwari Barat hanya berupa membasmi jentik dan nyamuk dewasa melalui penyemprotan insektisida saja. Kegiatan itu hanya dilakukan jika di daerah tersebut pernah atau sudah terjadi KLB. Penyemprotan insektisida di daerah prioritas bertujuan untuk menurunkan kasus Malaria di Kecamatan Manokwari Barat.

Upaya membunuh jentik dan nyamuk dewasa melalui penyemprotan insektisida, larvaciding, dan biological control sesungguhnya sangat efektif dalam menurunkan kasus Malaria, namun jika kegiatan tersebut tidak dilakukan secara berkelanjutan tentu menjadi ancaman bagi masyarakat khususnya daerah endemik Malaria seperti Manokwari. Penyemprotan insektisida memerlukan kesadaran masyarakat agar lebih proaktif dalam melakukan upaya pencegahan Malaria seperti pelaporan kasus Malaria apabila ada warga yang sakit dan menjaga kondisi lingkungan agar tetap bersih. Petugas kesehatan juga harus proaktif turun ke lapangan untuk melakukan Survei Malariometrik dasar agar dapat mengetahui kondisi masyarakat dan kondisi lingkungan yang rawan terjadi kasus Malaria di wilayah kerjanya.

Timbulnya berbagai masalah kesehatan dapat timbul akibat perilaku masyarakat yang tidak menjaga perilaku hidup bersih dan sehat. Ahli kesehatan masyarakat telah sepakat bahwa untuk mengatasi perilaku diperlukan suatu upaya dalam proses pendidikan kesehatan masyarakat. Melalui proses tersebut diharapkan terjadinya perubahan perilaku menuju tercapainya perilaku sehat. Proses perubahan ini, perlu ditunjang dengan perubahan sikap dan pengetahuan (Mirontoneng, Ismanto and Malara, 2014).

Penelitian ini sejalan dengan penelitian di Provinsi Maluku Utara. Upaya pengendalian Vektor Malaria selama tahun 2010 dilakukan melalui penyemprotan rumah pada enam desa. Jumlah bangunan yang disemprot sebanyak 743 yang terdistribusi di empat desa di Kota Tidore Kepulauan, Halmahera Selatan, dan Halmahera Tengah masing-masing 1 desa. Penyemprotan hanya pada desa peningkatan kasus, mengingat adanya keterbatasan anggaran yang tersedia (Lestari, 2012).

Penilitian ini juga sejalan dengan penelitian di Kabupaten Bulukumba, Sulawesi Selatan. Kegiatan penyemprotan rumah seharusnya dilakukan sebagai upaya pengendalian vektor Malaria, namun kegiatan penyemprotan hanya difokuskan pada wilayah dengan kasus Malaria tertinggi di setiap wilayah kerja puskesmas. Penyemprotan pada rumah warga dilakukan oleh pihak Dinas Kesehatan Kabupaten Bulukumba dan bekerja sama dengan pihak puskesmas setempat (Ardiansyah, Susilawaty and Nurdiyanah, 2015).

\section{Kebiasaan Berada di Luar Rumah pada Malam Hari}

Kebiasaan mayoritas masyarakat Manokwari yang sering berada di luar rumah hingga larut malam merupakan salah satu factor risiko penyebab Malaria. Kebiasaan buruk ini menjadi faktor yang lebih bersifat spesifik dan eksofagi yang akan memperbanyak jumlah gigitan nyamuk Anopheles. Nyamuk Anopheles lebih senang menggigit pada malam hari. Aktifitas nyamuk Anopheles yang berlangsung sepanjang malam, sejak sekitar pukul 18.30-22.00 waktu setempat. Perilaku nyamuk Anopheles lainnya yang merupakan faktor risiko bagi masyarakat yang mempunyai kebiasaan berada di luar rumah pada malam hari adalah adanya golongan eksofagi 
(golongan nyamuk yang suka menggigit di luar rumah) (Tallan and Mau, 2016).

Hasil wawancara dengan informan menjelaskan bahwa upaya pencegahan Malaria yang sering dilakukan jika sedang berada di luar rumah pada malam hari biasanya memakai lotion anti nyamuk dan mengantisipasi gigitan nyamuk dengan cara mengenakan pakai yang tebal, misalnya baju lengan panjang, jaket, serta celana panjang ataupun memakai sarung panjang. Upaya tersebut dianggap cukup efektif mencegah gigitan nyamuk sebab telah disadari oleh sebagian besar masyarakat bahwa nyamuk Malaria sangat aktif mengigit pada malam hari.

"Kalau keluar malam, Katong paling disini saja, dekat-dekat rumah toh, biasa kumpul sama tetangga, begitu sampai jam 10 malam to. Kalau tara mau digigigit nyamu suruh suami sama anak pake celana panjang', pake jaket kalau dingin. Disini kan katong kadang dingin kadang panas, jadi kalau dingin pake jaket to." (NC, 35 tahun).

Informan menyatakan bahwa jika suami dan anaknya keluar pada malam hari biasanya menyarankan untuk menggunakan celana panjang atau menggunakan jaket supaya terhindar dari gigitan nyamuk. Faktor cuaca yang tidak menentu juga kadang menyebabkan banyak nyamuk disekitar rumahnya.

"Katong biasa. Pake baju lengan pende', celana pendek saja, tapi pake sarung, bikin selimut' supaya tara digigi nyamuk, nyamuk bagitu paling sering gigi katong pebetis, makanya pakai sarung to." (RB, 30 tahun).

Informan menyatakan bahwa jika keluar rumah pada malam hari, sudah terbiasa memakai baju lengan pendek dan celana pendek saja. la juga memakai sarung panjang untuk melindungi diri agar terhindar gigitan nyamuk, sebab betis merupakan bagian tubuh yang paling sering digigit nyamuk.

“lyo', biasa. paetua keluar depan rumah sama pe teman main domino sampe tengah malam. Pake baju pende', celana pende saja'tapi petuah pakai minyak anti nyamu toh supaya tidak digigi nyamuk." (HM, 45 tahun).

Informan menyatakan bahwa suaminya sering keluar pada malam hari, tinggal di depan rumah bermain domino hingga tengah malam dengan mengenakan baju dan celana pendek saja. Suami informan memilih untuk memakai lotion anti nyamuk sebelum keluar rumah menghindari gigitan nyamuk.

“Kalo pe'tuah pergi cari ikan sampai subuh, petuah tara pernah lepas pake sarung, kadang pake celana pendek saja. Pake baju kaos panjang toh" supaya tara gigi nyamuk." (MT, 30 tahun).

Informan menyatakan bahwa apabila suaminya hendak pergi mencari ikan selalu memakai baju kaos panjang dan celana pendek. la mengungkapkan bahwa suaminya tidak pernah lepas untuk menggunakan sarung panjang agar terhindar dari gigitan nyamuk.

"Biasa, kaluar ke rumah kaka' paling. Lengan pende' saja, katong sampai setengah jam, 1 jam. So biasa pake autan supaya tara gigi nyamuk." (DM, 35 tahun).

Informan menyatakan bahwa jika keluar rumah pada malam hari hanya mengenakan pakaian lengan pendek saja, la juga mengungkapkan bahwa selalu menggunakan autan (lotion anti nyamuk) sebagai upaya antisipasi agar tidak digigit nyamuk.

Hasil wawancara dengan seluruh informan menunjukkan bahwa kebiasaan masyarakat berada di luar rumah pada malam hari sudah menjadi kebiasaan masyarakat. Berbagai alasan sering keluar pada malam hari tergantung kepentingan masing-masing. Pekerjaan suami informan yang umumnya bekerja sebagai nelayan mengharuskan beraktivitas pada malam hari ini berisiko digigit nyamuk anopheles. Pencegahan terhadap gigitan nyamuk tidak dilakukan secara terus menerus, sekalipun berbagai cara telah dilakukan masyarakat agar tidak digigit nyamuk saat berada diluar rumah pada malam hari. Pencegahan yang dilakukan seperti memakai baju, celana panjang dan bahkan sebagian besar menggunakan sarung panjang saja untuk dijadikan 
selimut bila cuaca bersuhu dingin. Penggunaan lotion anti nyamuk juga menjadi pilihan praktis bagi yang sudah terbiasa keluar pada malam hari. Masyarakat sudah melakukan antisipasi secara sederhana namun tetap berpotensi digigit nyamuk, sebab disadari atau tidak mereka berada didaerah endemik Malaria yang tentunya sangat rawan menderita atau tertular Malaria.

Sejumlah penelitian juga menyatakan bahwa buruknya kebiasaan dan sikap masyarakat merupakan salah satu faktor pendukung penyebab Malaria. Contoh perilaku masyarakat yang mempermudah terjadinya kejadian Malaria yaitu kebiasaan masyarakat berada di luar rumah pada malam hari, kebiasaan tidur tidak menggunakan kelambu, dan tidur tanpa menggunakan obat anti nyamuk (Tallan and Mau, 2016).

Penelitian ini sejalan yang dilakukan Di Desa Sokoagung, Kecamatan Bagelen, Kabupaten Purworejo. Kasus Malaria yang ditemukan terjadi karena aktifitas laki-laki muda mengambil nira kelapa pada petang hingga malam hari serta pertemuan warga yang dilakukan di malam hari. Sementara itu, pada perempuan dapat terjadi karena aktifitas membuat gula kelapa hingga malam hari tanpa perlindungan dari gigitan nyamuk. Kondisi tersebut juga didukung dengan desain rumah yang tidak rapat serangga (insect proofing) serta adanya risiko kebiasaan tidak melakukan perlindungan diri terhadap gigitan nyamuk saat di luar rumah pada malam hari (Sholichah et al., 2015).

Penelitian ini juga sejalan yang dilakukan di Desa Sudorogo Kecamatan Kaligesing Kabupaten Purworejo. Aktivitas masyarakat di luar rumah malam hari didukung karena adanya kegiatan keagamaan yang dilakukan secara bergilir dari rumah ke rumah setiap minggunya. Selain itu, ada juga yang sekedar pergi ke warung membeli kebutuhan dan pergi menonton televisi ke rumah tetangga. Kegiatan rutin lainnya yang dilakukan saat malam hari adalah shalat berjamaah di mushola. Berbagai kebiasaan ini dapat mempermudah terjadinya kontak dengan nyamuk Anopheles (Alami and Adriyani, 2016).

Hasil studi lain di Desa Konda Maloba menyebutkan, penularan Malaria masih tinggi terjadi pada saat masyarakat berada di luar rumah. Penularan ini dapat terjadi karena adanya perilaku dan aktifitas masyarakat yang banyak dilakukan di luar rumah, seperti bermalam di kebun saat musim menanam atau panen tanpa menggunakan pelindung diri untuk menghindari gigitan nyamuk (Sopi, 2015).

Indonesia memiliki berbagai suku bangsa dengan ragam kebiasaan dan perilaku, yang merupakan faktor berpengaruh dalam menunjang keberhasilan partisipasi masyarakat dalam program pengendalian Malaria. Sejumlah studi yang sudah pernah dilakukan di Jawa Tengah, Jawa Barat, NTB (Lombok), Riau, dan Papua (Timika) menunjukkan bahwa perilaku yang tidak menunjang dalam upaya pengendalian Malaria ini adalah kebiasaan berada di luar rumah sampai larut malam. Perilaku tersebut dapat mempermudah kontak dengan nyamuk Anopheles, apalagi nyamuk yang memang sifatnya lebih suka beristirahat dan menggigit di luar rumah (Kemenkes RI, 2011).

Hasil analisis tentang kebiasaan masyarakat di luar rumah pada malam hari di Kecamatan Manokwari Barat menjadi salah satu determinan Malaria jika tidak melakukan upaya antisipasi. Upaya antisipasi yang dapat dilakukan yakni dengan menggunakan baju lengan panjang dan celana panjang, memakai sarung, serta menggunakan lotion anti nyamuk. Diperlukan sosialisasi untuk meningkatkan kesadaran masyarakat yang tinggal di daerah endemis Malaria agar mengubah kebiasaan keluar rumah pada malam hari. Upaya ini perlu dilakukan sebagai langkah yang paling efektif agar tidak digigit nyamuk Malaria (Anopheles).

\section{Penggunaan Kelambu}

Penggunaan kelambu sebagai salah satu metode untuk mencegah gigitan nyamuk telah dilakukan sejak jaman dahulu. Pengalaman tersebut sampai sekarang masih ditemukan diberbagai pelosok kampung, hanya saja penggunaan kelambu di daerah perkotaan sudah jarang ditemui. Masyarakat kota menganggap hal ini merupakan perilaku primitif, padahal sesungguhnya penggunaan kelambu dapat mencegah gigitan nyamuk. Saat ini bahkan telah disediakan kelambu berinsektisida yang sangat efektif mencegah gigitan nyamuk anopheles yang dapat menyebabkan Malaria. 
Kementerian

Kesehatan melakukan pembagian kelambu anti nyamuk sebagai salah satu upaya untuk menurunkan penularan Malaria di daerah endemis Malaria. Upaya in idilakukan karena dinilai efektif dalam memberikan perlindungan pada masyarakat dari gigitan nyamuk Anopheles. Di tahun 2017 dan 2018, Kementerian Kesehatan telah membagikan 2.824.450 buah kelambu anti nyamuk di 3 provinsi kawasan timur indonesia dengan rincian Papua 1.214.750, Papua Barat 485.700, dan NTT 1.124.000 (Biro Komunikasi dan Pelayanan Masyarakat, 2017).

Hasil wawancara dengan informan tentang pemakaian kelambu ketika tidur malam tidak dilakukan secara konsisten. Tidak semua masyarakat memiliki kelambu berinsektisida, dan bahkan mereka tidak mendapatkan pembagian kelambu oleh petugas kesehatan. Kelambu berinsektisida hanya diberikan kepada keluarga yang memiliki ibu hamil. Masyarakat juga kesulitan membeli kelambu berinsektisida karena harganya yang relatif mahal dan tidak tersedia dipasaran secara bebas. Mayoritas masyarakat beranggapan bahwa tidur di dalam kamar tidak perlu memakai kelambu karena terasa panas, kecuali bila tidur di luar kamar. Kelambu insektisida juga tidak dipakai karena penggunaannya yang dianggap merepotkan sebab harus dibongkar pasang. Alasan ini yang menyebabkan masyarakat lebih memilih menggunakan obat nyamuk saja untuk mencegah gigitan nyamuk, sebagaimana kutipan wawancara berikut:

"Kadang-kadang katong pake kelambu, kadang tidak. Kalo di kamar pake kelambu, kalo di luar tidak pake kelambu, obat nyamuk saja. Kelambunya di beli, kecuali ibu hamil dapat kelambu pembagian." (NC. 30 tahun).

Informan menyatakan penggunaan kelambu tergantung tempat tidur yang mereka gunakan. Saat tidur di kamar mereka tidak memakai kelambu dan saat tidur di luar kamar, mereka lebih memilih menggunakan obat nyamuk. Kondisi ini disebabkan karena mereka enggan untuk membeli kelambu, sementara kelambu yang dibagikan hanya pada keluarga yang memiliki ibu hamil.
"Tara pakai' panas. Pake obat nyamuk dorang panas toh." (RB, 30 tahun).

Informan menyatakan, dia tidak menggunakan kelambu karena gerah. la hanya menggunakan obat nyamuk.

“Tra pakai', tarada kelambu jo." (HM, 45 tahun).

Informan menyatakan bahwa dia tidak menggunakan kelambu saat tidur malam karena dia tidak memiliki kelambu.

“Tara pake', pake kelambu panas jo.” (MT, 30 tahun).

Informan menyatakan bahwa dia tidak menggunakan kelambu waktu tidur malam karena gerah.

“Tarada uang', dorang tarada uang pake beli kelambu." (DM, 35 tahun).

Informan menyatakan bawa dia tidak memakai kelambu sebab tidak memiliki uang untuk membeli kelambu. Hasil penelitian menunjukkan bahwa sebagian besar informan menyatakan bahwa pembagian kelambu hanya diperuntukkan bagi ibu hamil dibenarkan oleh petugas kesehatan sebab selain dari terbatasnya jumlahnya kelambu, risiko, dan dampak Malaria bagi ibu hamil sangat berbahaya bagi ibu hamil dan bayi yang akan dilahirkan. Kasus kejadian Malaria banyak terjadi di Manokwari, oleh karena itu ibu hamil ditetapkan sebagai sasaran prioritas untuk mendapatkan bantuan kelambu insektisida, sebagaimana kutipan dibawah ini:

"Cuma ibu hamil saja kita kasi kelambu kah cuma mereka yang rutin datang ke puskesmas, apakah warga punya kelambu atau tidak? Kita tidak tahu, sebab ada juga warga yang biasa beli langsung, Cuma kelambu tidak dijual bebas dipasar, dan harganya mahal, tapi kalau ibu hamil dan ibu menyusui kita wajib kasikan kelambu sebab dampaknya sangat besar yang bisa menyebabkan kematian bagi ibu dan bayi yang dilahirkan." (IW, 25 tahun). 
Wawancara dengan petugas kesehatan menjelaskan bahwa terdapat beberapa alasan tidak menggunakan kelambu. Sebagian besar masyarakat tidak memakai kelambu secara konsisten oleh karena beberapa alas an, diantaranya tidak memiliki kelambu, terasa panas atau gerah, dan pemasangan yang cukup rumit karena harus dibongkar pasang sebelum dan sesudah dipakai. Masyarakat yang tidak memiliki kelambu insektisida harus membeli, sementara mereka tidak memiliki uang dan merasa kesulitan untuk membeli sebab kelambu tersebut jarang dijual dipasaran serta harganya yang relatif mahal.

$$
\text { Penggunaan kelambu tidak }
$$

maksimal di Kecamatan Manokwari Barat, karena masyarakat yang sudah memiliki kelambu dengan alasan membeli sendiri dan tidak rutin memakai kelambunya saat tidur malam. Apabila pemerintah ingin membuat program kelambunisasi (pemberian kelambu) gratis, sebaiknya tidak hanya diperuntukkan bagi ibu hamil saja, tetapi juga seluruh masyarakat, karena kasus Malaria banyak juga terjadi pada anak sekolah.

Penelitian serupa yang telah dilakukan di wilayah kerja Puskesmas Kayeli, Kecamatan Wayapo, Kabupaten Buru, Maluku. Penggunaan kelambu berinsektisida menimbulkan efek nyaman bagi masyarakat. Kondisi ini disebabkan karena masyarakat mnganggap mereka dapat terhindar dari gigitan nyamuk dan ancaman Malaria. Masyarakat juga menunjukkan sikap positif terhadap penggunaan kelambu, bahkan penggunaan kelambu merupakan sebuah perilaku yang wajib dilakukan (Wael, Thaha and Riskiyani, 2013).

Studi lain yang dilakukan di Kabupaten Mamuju, Sulawesi Barat menunjukkan bahwa masyarakat memiliki keyakinan bahwa pemakaian kelambu dapat memproteksi diri dari gigitan nyamuk Anopheles. Atas dasar tersebut, umumnya masyarakat menggunakan kelambu meskipun kelambu yang digunakan adalah kelambu yang hanya dibeli di pasaran dan berinsektisida (Harpenas, Syafar and Ishak, 2017).

Penelitian sebelumnya di Desa

Bumi Kawa, Kecamatan Lengkiti, Kabupaten Ogan Komering Ulu menunjukkan hasil bahwa semua kelambu yang diuji memiliki angka knockdown nyamuk < 95\% dengan angka kematian nyamuk < $80 \%$. Angka tersebut menjelaskan bahwa efektifitas seluruh kelambu berinsektisida yang diuji sudah sangat berkurang. Kondisi ini disebabkan karena kelambu sudah digunakan dalam jangka waktu lama, yakni berkisar 2 - 3 tahun dan lebih dari 3 tahun (Rahmadiliyani and Noralisa, 2013).

\section{Pemakaian Obat Anti Nyamuk}

Pencegahan Malaria dapat juga dilakukan melalui pemakaian obat anti nyamuk. Upaya ini sebagai alternatif bagi yang tidak dapat menggunakan kelambu secara konsisten. Obat anti nyamuk selain dapat dibeli dengan harga yang relatif murah juga mudah ditemui dipasaran. Berbagai jenis obat anti nyamuk diantaranya obat nyamuk bakar (fumigon), obat nyamuk semprot (aerosel), bahkan sekarang ini sudah tersedia obat nyamuk elektrik, dan obat nyamuk oles (mosquito repellent).

Hasil wawancara dengan sebagian besar informan diperoleh informasi bahwa masyarakat memakai obat nyamuk sebelum tidur sebagai upaya mencegah Malaria. Jenis obat nyamuk yang sering digunakan yaitu obat nyamuk bakar (baygon) karena harganya relatif lebih murah dibandingkan dengan obat nyamuk oles maupun semprot. Obat nyamuk bakar yang dibeli dengan harga Rp.500 (lima ratus rupiah) dapat dipakai hingga 2 malam, sementara obat nyamuk oles hanya bisa dipakai untuk 1 malam saja, sebagaimana hasil wawancara berikut;

"Pake obat nyamu', baygon, bakar. Hmm, lebih anu kalo baygon, tara' mempan karna disini banya' sekali nyamu'." (NC. 35 tahun).

Informan menyatakan bahwa dia memakai obat nyamuk bakar (Baygon) karena lebih ampuh membunuh nyamuk yang banyak di rumahnya dibanding obat nyamuk jenis lainnya.

"Eh, bakar saja. tara biasa dong pake obat nyamuk laen." (BM, 32 tahun)

Informan menyatakan bahwa dia memakai obat nyamuk bakar karena dia tidak biasa memakai obat nyamuk jenis lain. 
"Pake, bakar saja. Tra beli semprot', bakar saja karna murah, menghemat." (HM, 45 tahun).

Informan beranggapan bahwa obat nyamuk bakar lebih murah dan hemat dibanding obat nyamuk lain.

"Dorang beli obat nyamuk Bakar saja, tra ada uang." (MT, 30 tahun).

Informan mengatakan bahwa dia memakai obat nyamuk bakar karena tidak memiliki uang membeli obat nyamuk lain seperti semprot (aerosol).

“Yang dorang pake' ya, obat nyamu' yang 500, bakar saja toh. Kalo Autan, 5001 malam saja, kalao bakar 2 malam, hemat kita toh." (SY, 26 tahun).

Informan mengatakan bahwa dia memakai obat nyamuk bakar karena lebih hemat dibanding obat nyamuk lain (oles) seperti Autan. Obat nyamuk bakar dapat dibeli dengan harga 500 rupiah dan bisa digunakan untuk 2 malam sedangkan Autan hanya dipakai untuk 1 malam saja.

“Pake, bakar. tarada' uang beli yang semprot, hemat juga yang bakar, 500 sudah bisa di pake 2 malam." (PS, 35 tahun)

Informan mengatakan dia memakai obat nyamuk bakar karena tidak memiliki uang membeli obat nyamuk semprot dan obat nyamuk bakar lebih hemat karena 500 rupiah sudah bisa digunakan untuk 2 hari. Hasil wawancara dengan keseluruhan informan menjelaskan bahwa penggunaan obat anti nyamuk bervariasi tergantung daya beli masing-masing individu. Dengan mengeluarkan biaya yang relatif murah mereka juga sudah mampu menjamin dirinya untuk tidak digigit nyamuk. Mereka mengeluarkan uang Rp.500,- dan sudah bisa mencegah gigitan nyamuk selama 2 malam. Obat nyamuk bakar dinilai lebih hemat dari segi biaya dibanding obat nyamuk oles dan obat nyamuk semprot.

Penelitian ini sejalan yang dilakukan di wilayah kerja Puskesmas Seira yang menunjukkan bahwa kebanyakan masyarakat tidak menyukai aroma yang dikeluarkan dari obat anti nyamuk bakar. Alasan inilah yang membuat masyarakat tersebut tidak menggunakan obat anti nyamuk bakar tersebut. Disamping itu, juga ada yang sebagian kecil masyarakat masih tetap menggunakan obat anti nyamuk. Ada yang menggunakan jenis obat anti nyamuk bakar, namun hanya menggunakan pada waktu tertentu saja. Penggunaan obat anti nyamuk bakar misalnya saat musim hujan, dimana pada waktu tersebut populasi nyamuk semakin bertambah. Warga juga ada yang hanya membakar serabut kelapa untuk mengusir nyamuk. Masyarakat sejauh ini telah menyadari pentingnya menghindari diri dari gigitan nyamuk, namun belum maksimal melakukan upaya pencegahan dengan penggunaan obat anti nyamuk ini (Lololuan, Riskiyani and Ibnu, 2013).

Penelitian ini tidak sejalan dengan penelitian yang pernah dilakukan di Puskesmas Rumbia Tengah. Hasil penelitian menegaskan bahwa masyarakat tidak memilih untuk menggunakan obat anti nyamuk bukan karena harganya yang lebih murah dibandingkan dengan upaya pencegahan lainnya. Masyarakat tidak memakai obat anti nyamuk karena alasan mengganggu kenyamanan (Engka, Rezal and Afa, 2017).

Dampak penggunaan obat nyamuk terhadap kesehatan penting diketahui oleh masyarakat, khususnya bagi yang sering menggunakan obat anti nyamuk bakar. Penggunaan obat anti nyamuk bakar dapat berisiko bagi kesehatan, asapnya mengandung zat karsinogen yang dapat berakibat kerusakan serius pada hidung, tenggorokan, dan jaringan paru manusia. Perubahan yang terjadi pada paru-paru setelah terpapar obat nyamuk bakar dan obat nyamuk elektrik selama 6 jam mengakibatkan pengecilan pada paru karena terjadi kolaps paru (Rianti, 2017).

Berbagai jenis obat nyamuk yang sering digunakan oleh masyakat sebagai tindakan yang dilakukan untuk mencegah penularan Malaria adalah jenis obat nyamuk elektrik yang berukuran $3 \times 2 \mathrm{~cm}$ dan terbuat dari lembar lapik (Mat) mengandung insektisida yang mudah diuapkan, misalnya bioallethrin dan $d$ allethrna. Selain itu, banyak juga obat nyamuk oles (Repellent) dalam berbagai merk yang dikemas dalam bentuk cairan oles atau krim dan spray. Jenis obat nyamuk oles ini semuanya mempunyai fungsi yang sama, yaitu sebagai zat 
penolak dari gigitan nyamuk Anopheles penyebab Malaria.

Penggunaan Kawat Kasa di Jendela dan
Ventilasi Rumah
Daerah tropis memang menjadi
ancaman terhadap tempat
berkembangbiaknya nyamuk dan serangga, oleh karena itu, masyarakat yang tinggal daerah tropis dan endemis Malaria sedapat mungkin melakukan antisipasi agar terhindar dari gigitan nyamuk, termasuk Anopheles. Obat nyamuk yang selama ini digunakan oleh masyarakat seperti obat nyamuk bakar, semprot, dan oles tentu saja memiliki risiko bagi kesehatan karena mengandung zat karsinogen. Masyarakat perlu mendapat penyuluhan tentang cara mengantisipasi risiko tersebut dengan cara alamiah dan ramah lingkungan. Cara tersebut dapat dilakukan dengan memasang kawat kasa pada jendela dan ventilasi rumah.

Pemasangan kasa nyamuk sangat efektif untuk mencegah nyamuk Anopheles masuk ke dalam rumah, sehingga rumah terhindar dari nyamuk selama 24 jam setiap harinya. Berbagai keuntungan lain yang dapat dirasakan yaitu suasana rumah lebih asri dan indah dipandang mata. Masyarakat juga tidak perlu mengeluarkan uang setiap hari untuk membeli obat nyamuk karena kawat kasa ini dapat bertahan dalam jangka waktu yang lama.

Hasil wawancara dengan informan menjelaskan bahwa mereka tidak memasang kawat kasa pada jendela dan ventilasi rumah dengan berbagai alas an. Alasan tersebut antara lain seperti tidak memiliki uang. Mereka beranggapan bahwa dengan memasang tirai/gorden juga dapat mencegah nyamuk masuk ke dalam rumah, serta adanya asumsi masyarakat bahwa dengan memasang plastik bening pada ventilasi juga mampu mencegah nyamuk dalam rumahnya, sebagaimana petikan wawancara berikut:

"Tarada', tara punya kawat kasa, so ada penutupnya toh." (NC. 35 tahun).

Informan mengatakan bahwa dia tidak memasang kawat kasa karena jendela dan ventilasi rumahnya sudah ada penutupnya.
"Tarada doi' pake beli kawat, klo ada uang katong pake beli kebutuhnan makan saja." (RB, 30 tahun).

Informan mengatakan bahwa tidak memasang kawat kasa sebab tidak memiliki uang untuk membeli kawat kasa. la lebih memilih untuk membeli keperluan makanan saja.

"Tarada, tra pake memang, pake kayu sama kain, tarada ongkos." (HM, 45 tahun).

Informan mengatakan bahwa dia tidak memasang kawat kasa karena tidak memiliki uang. Dia hanya memakai jendela kayu dan kain sebagai penutup jendela.

"Tarada', tarada ongkos beli kawat kasa, dong pakai yang ada saja." (MT, 30 tahun).

Informan mengatakan tidak memasang kawat kasa karena tidak memiliki uang untuk dipakai membeli kawat kasa.

"Tarada', Cuma pake kain gorden saja,ya tida' ada dana untuk beli." (DM, 35 tahun).

Informan mengatakan bahwa tidak memasang kawat kasa karena dia sudah memakai kain gorden dan tidak punya uang untuk membeli kawat kasa.

"Tarada plastik saja kasian, plastik itu jo, biasa hujan, kurang dana juga." (SY, 26 tahun).

Informan mengatakan tidak memasang kawat kasa sebab sudah memasang plastik di rumahnya. Selain karena anti hujan, dia juga tidak punya uang lebih untuk membeli kawat kasa.

"Tarada ada doi pake beli kawat kasa" (PS, 35 tahun)

Informan mengatakan tidak memasang kawat kasa sebab tidak memiliki uang untuk membeli kawat kasa.

Hasil wawancara dengan keseluruhan informan mengungkapkan bahwa masyarakat tidak memasang kawat kasa pada jendela dan ventilasi rumahnya 
dengan alasan bahwa jendelanya terbuat dari kayu dan sudah ada kain tirai/gorden. Kondisi tersebut, dirasa cukup untuk mencegah masuknya nyamuk dalam rumahnya, selain itu, kebutuhan hidup seharinya-hari lebih penting dari pada membeli kawat kasa, khususnya bagi mereka yang tidak memiliki uang untuk membeli kawat kasa tersebut.

Pemasangan kawat kasa tidak dilakukan masyarakat karena sebagian rumah yang ada di Kecamatan Manokwari Barat konstruksinya masih semi permanen dengan jendela rumah dari kayu. Disamping itu, pendapatan masyarakat tidak mencukupi untuk pengadaan kawat kasa tersebut. Status ekonomi masyarakat yang masih rendah menjadi salah satu penyebab bertambahnya penderita Malaria di kabupaten Manokwari.

Penelitian ini juga sejalan dengan penelitian di Kabupaten Asmat, Papua. Penelitian tersebut menyebutkan, faktor lingkungan lain yang memungkinan terjadinya Malaria adalah rumah berdinding kayu dengan kerapatan yang kurang dibandingkan dengan rumah berdinding beton. Selain itu, masih banyak rumah yang tidak memakai kawat kasa pada ventilasi, meskipun pemerintah setempat telah menggalakkan penggunaan kawat kasa, terutama di rumah-rumah gratis yang dibangun oleh pemerintah (Debora et al., 2018).

Hasil studi ini didukung oleh penelitian di wilayah kerja Puskesmas Kayeli, Kecamatan Wayapo, Kabupaten Buru, Maluku yang menunjukkan bahwa secara umum masyaarakat tidak menggunakan kawat kasa/ram pada ventilasi rumah mereka. Masyarakat mengaku bahwa mereka tidak memiliki uang untuk membeli kawat kasa/ram (Wael, Thaha and Riskiyani, 2013).

\section{Program Pencegahan Malaria di Puskesmas Wosi \\ Pelayanan kesehatan kepada} masyarakat di Kecamatan Manokwari Barat untuk mencegah penularan dan pengobatan Malaria sudah berjalan dengan baik, meski belum bisa dikatakan maksimal. Kondisi ini sebagaimana penjelasan yang diberikan oleh petugas kesehatan di Puskesmas Wosi:

"Yang menjadi 'primadona' sekarang dalam pencegahan Malaria adalah kelambunisasi, pemberian kelambu gratis kepada ibu-ibu hamil. Kenapa ibu hamil? Karna ibu hamil sangat rentan terkena Malaria. Kalau penyuluhan itu dilakukan jika dilihat ada peningkatan jumlah kasus Malaria pada bulan yang satu dengan bulan yang lain pada tahun yang sama. Penyemprotan itu spraing namanya, itu dilakukan jika terjadi kejadian luar biasa atau kematian di suatu daerah." (IW, 25 tahun).

Program pencegahan Malaria yang dilaksanakan oleh Puskesmas Wosi yaitu:

a. Penyuluhan

Penyuluhan ini merupakan kegiatan pokok yang dilakukan oleh bagian promosi kesehatan di Puskesmas Wosi. Penyuluhan Malaria sudah rutin dilakukan pada kegiatan posyandu khususnya pada wilayah kerja Puskesmas Wosi kasus Malaria yang tinggi. Penyuluhan ini memang seharusnya rutin di setiap daerah sebab penyuluhan tentang Perilaku Hidup Bersih dan Sehat (PHBS) seperti pembersihan SPAL (Saluran Pembuangan Air Limbah) yang dapat menjadi tempat perindukan Malaria.

\section{b. Penyemprotan}

Penyemprotan dilakukan hanya bila terjadi KLB atau kematian di suatu daerah. Penyemprotan itu disebut spraying. Sedangkan penyemprotan yang disebut fogging merupakan program pencegahan Demam Berdarah Dengue (DBD). Kegiatan penyemprotan seharusnya dilakukan jika sudah terdapat kasus Malaria di suatu daerah, agar penyebaran nyamuk tidak berkembang dan kasus Malaria berkurang.

\section{c. Kelambunisasi (Pemberian Kelambu)}

Kelambunisasi dilakukan atas adanya bantuan donor agency, karena Manokwari dinilai masih menjadi daerah yang memiliki kasus Malaria yang cukup tinggi. Kelambunisasi berinsektisida seharusnya tidak hanya dilakukan pada ibuibu hamil, melainkan di setiap rumah di daerah endemis agar kasus Malaria tidak bertambah dan pencegahan Malaria benarbenar terlaksana dengan baik.

\section{SIMPULAN}

Upaya pencegahan Malaria pada masyarakat di Kecamatan Manokwari Barat seperti membunuh jentik dan 
nyamuk Malaria dewasa melalui penyemprotan rumah, larvaciding, dan biological control tidak pernah dilakukan oleh masyarakat. Masyarakat menganggap bahwa hal ini merupakan tanggung jawab petugas kesehatan. Tindakan yang dilakukan untuk mencegah gigitan nyamuk Anopheles kepada mereka yang memiliki kebiasaan berada di luar rumah pada malam hari yakni dengan memakai pakaian baju berlengan panjang, jaket, dan sarung panjang untuk menghindari gigitan nyamuk. Penggunaan kelambu saat tidur malam dilakukan, namun tidak rutin, hanya sesekali, dan ada juga yang tidak menggunakan kelambu sama sekali. Pemakaian obat anti nyamuk jenis obat nyamuk bakar, selain karena hemat juga terjangkau harganya buat mereka. Pemakaian kawat kasa pada jendela dan ventilasi rumah masyarakat tidak dilakukan, sebab beberapa rumah warga di Kecamatan Manokwari Barat merupakan bangunan semi permanen yang jendelanya terbuat dari papan dan hanya memakai plastik bening serta kain gorden sebagai penutup jendela. Program pencegahan Malaria di Puskesmas Wosi ada 3 (tiga) yaitu penyuluhan, penyemprotan dan pemberian kelambu, dan program andalan saat ini adalah pemberian kelambu (kelambunisasi).

\section{DAFTAR PUSTAKA}

Alami, R. and Adriyani, R. (2016) 'TINDAKAN PENCEGAHAN MALARIA DI DESA SUDOROGO KECAMATAN KALIGESING KABUPATEN PURWOREJO', Jurnal Promkes, 4(2), pp. 199-211.

Ardiansyah, E., Susilawaty, A. and Nurdiyanah, S. (2015) 'Studi Kasus Penatalaksanaan Manajemen Penanggulangan Malaria Di Kabupaten Bulukumba', Jurnal HIGIENE, 1(3), pp. 183-196.

Arsin, A. A. (2012) MALARIA DI INDONESIA Tinjauan Aspek Epidemiologi. Makassar: MASAGENA PRESS.

Biro Komunikasi dan Pelayanan Masyarakat, K. K. R. (2017) 'Lebih dari 2 Juta Kelambu Dibagikan di Kawasan Timur Indonesia - Sehat Negeriku', 25 April 2019.

Debora, J. et al. (2018) 'Prevalensi malaria di Asmat, Papua: Gambaran situasi terkini di daerah endemik tinggi', Journal of Community
Empowerment for Health, 1(1), pp. 11-19. doi: 10.22146/jcoemph.38309.

Dinas Kesehatan Provinsi Papua Barat (2018) Profil Kesehatan Papua Barat, Dinkes Provinsi Papua Barat. Manokwari, Papua Barat.

Engka, W. S. R., Rezal, F. and Afa, J. R. (2017) 'Studi Tentang Peran Serta Masyarakat Dalam Upaya Pencegahan Penyakit Malaria Di Puskesmas Rumbia Tengah Tahun 2016', Jurnal Ilmiah Mahasiswa Kesehatan Masyarakat, 2(5), pp. 1-8.

Harpenas, H., Syafar, M. and Ishak, H. (2017) 'PENCEGAHAN DAN PENANGGULANGAN MALARIA PADA MASYARAKAT DI KABUPATEN MAMUJU PROVINSI SULAWESI BARAT', Jurnal Kesehatan Manarang. Poltekkes Kemenkes Mamuju, 2(1), p. 33. doi: 10.33490/jkm.v2i1.11.

Kemenkes RI (2011) 'Buletin Jendela Data dan Informasi Kesehatan', Triwulan I, p. 33.

Kemenkes RI (2014) Pedoman Manajemen Malaria.

Kemenkes RI (2017) Profil Kesehatan Indonesia 2017. doi: 10.1002/qj.

Lestari, T. R. P. (2012) 'Pengendalian Malaria dalam Upaya Percepatan Pencapaian Target Millennium Development Goals', Kesmas: National Public Health Journal, 7(1), p. 22. doi: 10.21109/kesmas.v7i1.72.

Lololuan, M. J., Riskiyani, S. and Ibnu, I. F. (2013) Perilaku Masyarakat Dalam Pencegahan Penyakit Malaria Di Puskesmas Seira Kabupaten Maluku Tenggara Barat. Universitas Hasanuddin.

Mirontoneng, A. R., Ismanto, A. Y. and Malara, R. (2014) 'ANALISIS FAKTORFAKTOR YANG BERHUBUNGAN DENGAN KEJADIAN MALARIA PADA ANAK DI WILAYAH KERJA PKM TONA KECAMATAN TAHUNA KABUPATEN SANGIHE', Jurnal Keperawatan UNSRAT, 2(2).

Rahmadiliyani, N. and Noralisa, N. (2013) 'Hubungan Penggunaan Kelambu Berinsektisida dan Kejadian Malaria di Desa Teluk Kepayang Kecamatan Kusan Hulu Kabupaten Tanah Bumbu Tahun 2013', Jurnal Buski, 4(3).

Rianti, E. D. D. (2017) 'Mekanisme Paparan Obat Anti Nyamuk Elektrik dan Obat Anti Nyamuk Bakar terhadap Gambaran Paru Tikus', Inovasi, 12(2), pp. 58-68. 
Sholichah, Z. et al. (2015) 'MALARIA DI DESA SOKOAGUNG, KECAMATAN BAGELEN, KABUPATEN PURWOREJO: KARAKTERISTIK DAN FAKTOR RISIKO MALARIA IN SOKOAGUNG VILLAGE, BAGELEN SUB DISTRICT, PURWOREJO DISTRICT: CHARACTERISTIC AND RISK FACTORS OF MALARIA', BALABA, 11.No,01, pp. 51-48.

Sopi, I. I. P. B. (2015) 'Beberapa aspek perilaku Anopheles sundaicus di Desa Konda Maloba Kecamatan Katikutana Selatan Kabupaten Sumba Tengah', ASPIRATOR - Journal of Vector-borne Disease Studies, 6(2), pp. 63-72. doi: 10.22435/aspirator.v6i2.3634.63-72.
Tallan, M. M. and Mau, F. (2016) 'Karakteristik Habitat Perkembangbiakan Vektor Filariasis di Kecamatan Kodi Balaghar Kabupaten Sumba Barat Daya', ASPIRATOR Journal of Vector-borne Disease Studies, 8(2), pp. 55-62. doi: 10.22435/aspirator.v8i2.4243.55-62.

Wael, M. Y., Thaha, R. M. and Riskiyani, S. (2013) 'UPAYA PENCEGAHAN MALARIA OLEH MASYARAKAT DI WILAYAH KERJA PUSKESMAS KAYELI , KECAMATAN WAYAPO , KABUPATEN BURU . MALUKU', repository.unhas., pp. 1-11. 